\title{
PHYSICAL ACTIVITY AND GENDER DIFFERENCES: CORRELATES OF COMPLIANCE WITH RECOMMENDED LEVELS OF FIVE FORMS OF PHYSICAL ACTIVITY AMONG STUDENTS AT NINE UNIVERSITIES IN LIBYA
}

\author{
Walid El Ansari ${ }^{1}$, Khalid Khalil ${ }^{2}$, Diane Crone ${ }^{1}$, Christiane Stock ${ }^{3}$ \\ ${ }^{1}$ Faculty of Applied Sciences, University of Gloucestershire, Gloucester, United Kingdom \\ ${ }^{2}$ Higher Industrial Technology Institute, Misurata, Libya \\ ${ }^{3}$ Unit for Health Promotion Research, Institute of Public Health, University of Southern Denmark, Esbjerg, Denmark
}

\section{SUMMARY}

Aims: This cross-sectional survey assessed and compared by gender the levels and correlates of achieving the international guidelines recommendations on five forms of physical activity (PA) (walking, moderate PA, vigorous PA, moderate or vigorous PA - MVPA, and muscle-strengthening PA). We examined the associations between achieving the international guidelines recommendations on five forms of PA and a variety of sociodemographic, health and academic performance variables.

Methods: Data was collected across nine Libyan universities (2008-2009, representative sample of 1,300 undergraduates). A self-administered questionnaire assessed frequency and duration of PA/week for each form of PA. Cut-offs for recommended guidelines were set according to the American Heart Association.

Results: About $43.7 \%$ of students achieved the guidelines for muscle strengthening PA, $20.7 \%$ for walking, $11.2 \%$ for vigorous PA, $28.5 \%$ for MVPA, and $4.8 \%$ for moderate PA (excluding walking). Binary logistic regression showed that except for walking, males were consistently associated with achieving the guidelines recommendations for all other forms of PA. Students with higher health awareness were more likely to achieve the guidelines for vigorous PA and muscle strengthening PA. Better academic performance was associated with higher levels of muscle strengthening PA. Students at institutions in the East of Libya were less likely to achieve the guidelines for walking, vigorous PA or muscle strengthening PA as compared to students from the North. Students from the West of Libya were also less likely to walk or to engage in moderate PA than their peers from the North.

Conclusions: Overall, relatively low proportions of students achieved the recommended guidelines of PA. Female students were particularly at risk for low level of PA. Attention is required to national policies that promote active living, along with addressing the cultural, geographic and other barriers to engagement of young adult males and females in PA.

Key words: physical activity, university students, Libya, gender, college health

Address for correspondence: W. El Ansari, Faculty of Applied Sciences, University of Gloucestershire, Oxstalls Campus, Oxstalls Lane, Gloucester GL2 9HW, United Kingdom. E-mail: walidansari@glos.ac.uk

\section{INTRODUCTION}

Physical activity (PA) influences health outcomes, somatic and mental health problems, and physical fitness (1). Despite the positive effects of PA on health, life has become more sedentary and the decrease in PA has affected young people. While PA declines gradually with age, there are periods where this is more rapid. For instance, vigorous PA(VPA) declines from high school to college, where few students participate in collegiate athletics, a determinant of VPA (2). Indeed $40-50 \%$ of students were physically inactive (34). This raises concerns, as the transition from adolescence to adulthood is critical period to establish behavioural patterns that impact on long-term health and chronic disease risk (3).

During the last few decades, the Arab countries across the Eastern Mediterranean Region (EMR) have encountered evident changes in their demographic profiles, socioeconomic features and health status. Such transformations were equally reflected in changes in the lifestyle of these populations, where the increased access to modern amenities has influenced their PA levels (4). Certainly, the substantial lifestyle changes due to fast urbanisation, the high use of automobiles for personal travel, and institution of labour-saving domestic and workplace appliances, along with other features had extensive influence on reducing the everyday physical requirements, thus boosting sedentary lifestyles amongst these young people and adults $(5,6)$.

In Egypt, one third of college/university students were physically inactive (7). Similarly, a study conducted in Saudi Arabia found that among the 'moderately active' female university students, only $43 \%$ of the participants met the WHO moderate PA (MPA) guidelines, while 14\% met the VPA recommendations (8). 
Further, among the 'highly active' females, $24 \%$ did not fulfill the requirements for VPA (8). Likewise, a cross-sectional study of college students reported that only $33 \%$ met the recommended PA guidelines, highlighting the need for implementing interventions aimed at promoting the recommended levels of PA (9). Indeed, researchers found that the prevalence of overweight and obesity among female university students was $10.8 \%$ and $30.6 \%$, respectively, where limited PA was an important contributor to obesity (10). Others also reported insufficient PA in nearly 50\% of young adults (18-19 years old) (11).

Many variables are associated with various forms of PA. We focused on three groups of demographic, health and academic performance/educational achievement correlates since age, sex, health status, and motivation are associated with PA(12). For the demographic variables, e.g. gender, young adult males have higher PA levels than young adult females (13). Regarding age/year of study, others found a decrease of PA with increasing year of study and in the general population, PA decreases with age $(3,14)$.

As for the set of health variables, e.g. quality of life (QoL), research suggested that enhanced QoL could be viewed as a benefit of and motivator for PA (15). Certainly, PA contributes to multiple aspects of QoL, and social and emotional benefits are primary motivators and outcomes for participants (15). In addition, attitudes and health awareness could also have an impact on PA (16). The relationship between PA and body mass index (BMI) in adolescents and youth seems to be inconsistent but many studies could not demonstrate an association between the two variables (16). Nevertheless, gradients in PA behaviour in adults have been observed across weight groups.

In terms of academic achievement, research reported a positive association between PA and academic achievement $(17,18)$. Conversely, no direct association between PA and academic achievement was shown in other studies that used grade point average/general grade point average (13). There was no direct association between PA and grade even when using both subjective (self reported) and objective (actual module grade) measures of academic achievement (19).

Low PA levels among young adults represent an increasing problem that adversely affects their health. Better understanding of the factors that are associated with PA could help create effective interventions aimed at raising the PA levels. Whilst studies of PA of university students have been undertaken in many countries, although some dispersed studies have been implemented in some EMR countries, no such studies have been conducted in Libya. Very scant information on this topic in Libya has been published either in scientific/academic journals or as government/country reports. Given this scarcity of information, together with difficulties and barriers imposed by the previous political regime in accessing universities within Libya, such university populations of young adults are a considerably hard-to-reach group. The current study bridges these knowledge gaps, and these features collectively attach high importance to the contributions and findings of the current study.

This cross-sectional study is a survey of a representative sample of undergraduate students across nine Libyan universities and colleges during the academic year 2008-2009. The study assessed and compared by gender, the levels and correlates of five forms of PA (walking, moderate PA, vigorous PA, MVPA, muscle-strengthening PA) (20). We also examined the associations between the five forms of PA and four socio-demographic variables (gender, age, year of study, religion), four health variables (self-rated health status, health awareness, quality of life, BMI), and two academic performance/educational achievement variables (academic performance in comparison with one's peers and the importance attached to achieving good grades at university). The specific objectives were to:

- describe and compare the levels of five forms of PA of the sample by gender;

- assess the variables associated with achieving the recommended guidelines of each of the five forms of PA.

\section{MATERIALS AND METHODS}

The current analysis is premised on data collected as a part of a General Student Health Survey implemented in the Eastern Mediterranean Region countries, UK and other European countries (19, 21-27).

\section{Sample, Data Collection Procedures and Ethical Considerations}

The study received ethical approval by research and ethics committees at the participating institutions. A representative sample of students was sought at the universities by selecting courses that represented the different departments/faculties. Self-administered questionnaires were distributed to participants attending the selected classes, and collected after completion. Participation was voluntary, anonymous, and by completing the questionnaire, students agreed to participate. Data were confidential and protected. All data were computer-entered by the second author to maximize quality assurance and minimize data entry errors.

The questionnaire was administered to 2,100 students, with 1,567 completed questionnaires returned (response rate $\approx 74.6 \%$ ), of which 267 questionnaires were excluded (missing data), leaving 1,300 questionnaires for analysis (439 males, 33.8\%; 861 females, $66.2 \%$; M age 20.9 years, SD 2.4). Data were collected at 9 institutions (6 universities, 3 colleges) in 7 cities (Misurata, Sabha, Zawea, Sirt, Al Bida, Benghazi, Tripoli). Hence, the sample was representative of Libyan higher education institutions. Table 1 shows the sample by region/city. Many disciplines were represented: Agriculture, Business, Education, Law, Mechanical Engineering, Medical Science, Medical Technology, and other disciplines.

\section{Health and Well-being Questionnaire}

The questionnaire gathered general health and well-being data: socio-demographic variables (e.g., gender, age, year of study, religion), self-reported health (e.g., general health, health awareness, quality of life, height and weight), lifestyle behaviours (e.g. PA), and university related questions (academic performance and educational achievement). The questionnaire has been used and field-tested actoss different student populations (19, 21-29).

Self-rated general health (1 item): "How would you rate your health in general?" with a 5-point scale response format ( $1=$ excellent, 2 = very good, $3=$ good, $4=$ fair, $5=$ poor), similar wording was used by the American College Health Association (30-31). 
Table 1. Distribution of the sample by region and city

\begin{tabular}{|c|c|c|c|c|}
\hline Higher education institution & Location (region) & City & $\begin{array}{c}\text { Number } \\
\text { of participants }\end{array}$ & $\%$ of total sample \\
\hline \multicolumn{5}{|l|}{ Universities } \\
\hline University of Tripoli (previously Al-Fateh University) & North & Tripoli & 190 & 14.6 \\
\hline Benghazi University (previously Garyounis University) & West & Benghazi & 58 & 4.5 \\
\hline Omar El-Muktar University & East & Al Bida & 88 & 6.8 \\
\hline Sebha University & South & Sabha & 79 & 6.1 \\
\hline Sirt University (previously Tahadi University) & South & Sirt & 191 & 14.7 \\
\hline Misurata University (previously 7th October University) & West & Misurata & 463 & 35.6 \\
\hline \multicolumn{5}{|l|}{ Colleges } \\
\hline Higher Medical Technology Institute & West & Misurata & 71 & 5.5 \\
\hline Higher Industrial Technology Institute & West & Misurata & 72 & 5.5 \\
\hline Higher Computer Technology Institute & North & Al Zawea & 88 & 6.8 \\
\hline Total & & & 1,300 & 100 \\
\hline
\end{tabular}

Heath awareness (Keep an eye on health, 1 item): "To what extent do you keep an eye on your health?", with four point response scale ( $1=$ not at all, $4=$ very much).

Quality of life (1 item): "If you consider the quality of your life: How did things go for you in the last four weeks?" (5 categories, $1=$ very badly, $5=$ very well) (32).

$B M I$ (reported): based on self reported weight and height, BMI was calculated using Metric BMI Formula: BMI $\left(\mathrm{kg} / \mathrm{m}^{2}\right)=$ weight in kilograms/squared height $\left(\mathrm{m}^{2}\right)$, and employed to group participants as: underweight $\left(\mathrm{BMI}<18.5 \mathrm{~kg} / \mathrm{m}^{2}\right)$, normal $(18.5 \leq$ BMI $\left.<24.9 \mathrm{~kg} / \mathrm{m}^{2}\right)$, overweight $\left(25.0 \leq \mathrm{BMI}<29.9 \mathrm{~kg} / \mathrm{m}^{2}\right)$, and obese (BMI $\left.\geq 30.0 \mathrm{~kg} / \mathrm{m}^{2}\right)(33)$.

$V P A$ ( 2 items): "During the last 7 days, on how many days did you do VPA like heavy lifting, digging, aerobics, or fast cycling?" In a second question students were asked: "How much time did you usually spend doing VPA on one of those days?" A cut-off of $\geq 20$ minutes on $\geq 3$ days a week was used in the analysis (20).

MPA (2 items): "During the last 7 days, on how many days did you do moderate PA like carrying light loads, cycling at a regular pace or double tennis? Do not include walking. (Moderate activities refer to activities that take moderate physical effort and make you breathe somewhat harder than normal)". In a second question students were asked: "How much time did you usually spend doing MPA on one of those days?" We used a cut-off of $\geq 30$ minutes on $\geq 5$ days/week (20). Walking was excluded from MPA and employed as a separate item in order to specify the amount of typical daily walking PA.

MVPA was computed by combining together moderate PA and vigorous PA. All students who achieved either moderate or vigorous PA at recommended level were set as achieving MVPA (AHA guidelines for vigorous PA) (20).

Walking (2 items): "During the last 7 days, on how many days did you walk for $\geq 10$ minutes at a time? (includes walking at work and at home, walking to travel from place, and any other walking that you might do solely for recreation, sport, exercise, or leisure)". Participants answered 0-7 days. A second question asked: "How much time did you usually spend walking on one of those days?" We used a cut-off of $\geq 30$ minutes on $\geq 5$ days/ week because no separate guidelines exist for walking (20). We consciously separated walking from moderate PA (although walking could be considered as a form of MPA) in order to be able to assess the contribution of walking to moderate PA and compute the proportion of the sample which achieved walking guidelines recommendations (employing the MPA guidelines).

MSPA (1 item): "On how many of the past 7 days did you do exercises to strengthen or tone your muscles, such as push-ups, sit-ups, or weight lifting?" Participants answered 0-7 days. We used the cut-off of $\geq 2$ days/week (20).

Academic performance/Educational achievement (2 items): "How do you rate your performance in comparison with your fellow students?" (5 response categories, $1=$ much worse, $5=$ much better) (19). The second item was "How important is it for you to have good grades at university?" (4 categories, $1=$ not at all important, 4 = very important).

\section{Statistical Analysis}

We used SPSS 18.0 (SPSS Inc. Chicago, IL) to calculate frequencies and proportions and to conduct the statistical analyses (significance level set at $\mathrm{p}<0.05$ ). Differences in sample features and achieved recommended guidelines of PA by gender were analysed using Chi-square tests (in very few instances some of the cell numbers were slightly fewer than 15). Binary logistic regression (enter mode) examined the odds ratios and 95\% confidence intervals for the association between different covariates and five PA forms (walking, MPA, VPA, MVPA, MSPA) as dependent variables. We report Nagelkerke $\mathrm{R}^{2}$ (goodness-of-fit measure) and Homer and Lemeshow tests (goodness-of-fit test) for the logistic regression models.

\section{RESULTS}

\section{Characteristics of the Study Sample}

The majority of students were $<25$ years, and females were younger than males (Table 2). About half the students were in the first or second academic year, with more males than females. 
Table 2. Sample characteristics and achieved recommended guidelines of PA by gender

\begin{tabular}{|c|c|c|c|}
\hline & $\begin{array}{c}\text { Female } \\
\mathrm{N}=861(\%)\end{array}$ & $\begin{array}{c}\text { Male } \\
\mathrm{N}=439(\%)\end{array}$ & $\mathbf{P}$ \\
\hline \multicolumn{4}{|l|}{ Health variables } \\
\hline Health awareness (to some extent/very much) & $679(78.9)$ & $364(82.9)$ & 0.083 \\
\hline Self rated general health (very good/excellent) & $462(53.7)$ & $228(51.9)$ & 0.556 \\
\hline Quality of life (quite well/well) & $516(59.9)$ & $252(57.4)$ & 0.381 \\
\hline \multicolumn{4}{|l|}{ BMI } \\
\hline Underweight & $62(9.4)$ & $24(6.1)$ & \multirow{4}{*}{$<0.001$} \\
\hline Normal & $439(66.8)$ & $228(58.0)$ & \\
\hline Overweight & $130(19.8)$ & $106(27.0)$ & \\
\hline Obese & $26(4.0)$ & $35(8.9)$ & \\
\hline \multicolumn{4}{|l|}{ Demographic variables } \\
\hline \multicolumn{4}{|l|}{ Age } \\
\hline$<20$ & $251(29.2)$ & $109(24.8)$ & \multirow{4}{*}{0.007} \\
\hline $20-24.9$ & $560(65.0)$ & $288(65.6)$ & \\
\hline $25-29.9$ & $41(4.8)$ & $40(9.1)$ & \\
\hline$\geq 30$ & $9(1.0)$ & $2(0.5)$ & \\
\hline \multicolumn{4}{|l|}{ Year of study } \\
\hline Year 1 & $244(28.3)$ & $187(42.6)$ & \multirow{4}{*}{$<0.001$} \\
\hline Year 2 & $270(31.4)$ & $86(19.6)$ & \\
\hline Year 3 & $237(27.5)$ & $82(18.7)$ & \\
\hline$\geq$ Year 4 & $110(12.7)$ & $84(19.1)$ & \\
\hline \multicolumn{4}{|l|}{ Religion } \\
\hline Islam & $860(99.9)$ & $438(99.8)$ & \multirow{2}{*}{ N.C. } \\
\hline Other & $1(0.1)$ & $1(0.2)$ & \\
\hline \multicolumn{4}{|l|}{ Geographical region of Libya } \\
\hline North & $152(17.7)$ & $126(28.7)$ & \multirow{4}{*}{$<0.001$} \\
\hline South & $217(25.2)$ & $53(12.1)$ & \\
\hline East & $124(14.4)$ & $24(5.5)$ & \\
\hline West & $368(42.7)$ & $236(53.8)$ & \\
\hline \multicolumn{4}{|l|}{ Academic performance/Educational achievement variables } \\
\hline \multicolumn{4}{|l|}{ One's academic performance compared to peers } \\
\hline Much better & $62(7.2)$ & $25(5.7)$ & \multirow{5}{*}{$<0.001$} \\
\hline Better & $303(35.2)$ & $107(24.4)$ & \\
\hline The same & $404(49.6)$ & $238(54.2)$ & \\
\hline Worse & $78(9.1)$ & $53(12.1)$ & \\
\hline Much Worse & $14(1.6)$ & $16(3.6)$ & \\
\hline \multicolumn{4}{|l|}{ Importance of having good grades at University } \\
\hline Very important & $611(71.0)$ & $275(62.6)$ & \multirow{4}{*}{$<0.001$} \\
\hline Somewhat important & $219(25.4)$ & $129(29.4)$ & \\
\hline Not very important & $23(2.7)$ & $21(4.8)$ & \\
\hline Not at all important & $8(0.9)$ & $14(3.2)$ & \\
\hline \multicolumn{4}{|l|}{ Physical activity and muscle strengthening variables } \\
\hline Achieved recommended level of walking as moderate PA & $171(19.9)$ & $98(22.3)$ & 0.300 \\
\hline Achieved recommended level of other moderate $\mathrm{PA}^{\mathrm{a}}$ & $21(2.4)$ & $42(9.6)$ & $<0.001$ \\
\hline Achieved recommended level of vigorous $\mathrm{PA}^{\mathrm{a}}$ & $48(5.6)$ & $97(22.1)$ & $<0.001$ \\
\hline Achieved recommended level of any moderate or vigorous PA (MVPA) & $202(23.5)$ & $169(38.5)$ & $<0.001$ \\
\hline Strengthening exercises $\geq$ two times/week & $292(33.9)$ & $276(62.9)$ & $<0.001$ \\
\hline
\end{tabular}


Almost the whole sample was of Muslim faith, so religion was not examined in subsequent analyses.

Most students "kept an eye on their health" (health awareness) to some extent/very much, but $\approx 50 \%$ rated their health as very good/excellent; and $\approx 60 \%$ had quite well/well QoL. No gender differences were noted in these three health related variables. About 28.3\% were overweight/obese (more males than females). The majority (94.9\%) felt that having good grades at university was somewhat/very important, and importance of achieving good grades was more important for females. About $38.2 \%$ rated their own academic performance better/much better as compared to their peers, and this rating was higher among females.

\section{Achieved Recommended Guidelines of Five Forms of PA by Gender and by Region in Libya}

Table 2 also depicts the achieved guidelines of various PA forms. The highest percentage of students who achieved the guidelines recommendations was for MSPA (43.7\% of sample, $\geq 2$ times/week), with more males (62.9\%) than females (33.9\%). Walking was undertaken by $20.7 \%$ of the sample $\geq 5$ times/week for $\geq 30$ minutes with no gender difference. A small proportion (4.8\%), but significantly more males than females, achieved the MPA guidelines (excluding walking). Only $11.2 \%$ of the sample achieved the VPA guidelines, with more males $(22.1 \%)$ than females (5.6\%). As for MVPA, about $28.5 \%$ achieved the guidelines, with significantly more males (38.5\%) than females $(23.5 \%)$.

Figure 1 depicts the different forms of PA by region, where the prevalence of achieving the guidelines recommendations for all forms of PA were higher among students from the North of Libya (Tripoli University, Tripoli and Higher Computer Technology Institute, Zawea).

\section{Variables Independently Associated with Achieving Recommended Guidelines of Five Forms of PA}

Table 3 shows the binary logistic regression analyses with the achievement of guidelines for five PA forms as dependent variables, while adjusting for all other variables in the Table. Except for walking, males were consistently associated with achieving the

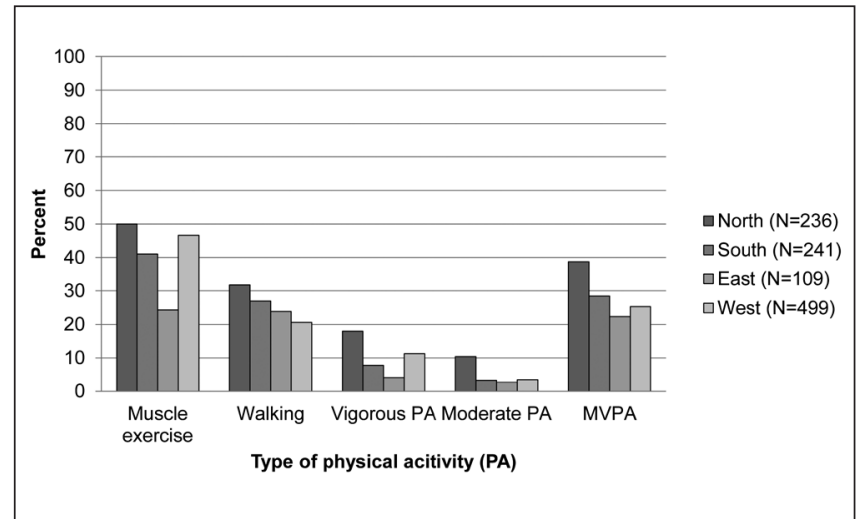

Fig. 1. Percentage of students achieving recommended levels of five forms of PA by geographical region in Libya.

Muscle exercise $=$ muscle strengthening exercises; MVPA = any moderate or vigorous $\mathrm{PA}$ guidelines for all other forms of PA. Students with higher health awareness (kept an eye on their health) were more likely to engage in VPA and MSPA. Better academic performance was associated with higher MSPA level. Students from the East of Libya were less likely to achieve the guidelines for walking, VPA, MVPA, or MSPA as compared to students from the North. Students from West Libya were also less likely to walk or to engage in MPA, or achieve the MVPA guidelines compared with their peers from the North. The variables included in the five models could best explain $\operatorname{MSPA}\left(\mathrm{R}^{2}=0.17\right)$ and least walking $\left(\mathrm{R}^{2}=0.02\right)$. In addition, the Homer and Lemeshow tests were insignificant $(\mathrm{p}>0.05)$ for all models, suggesting that the models fit well to the data. We found no significant associations between the health variables (health awareness - keep an eye on health, self-rated health, quality of life or BMI), or other demographic (age, year of study) or academic achievement variables (importance of good grades), and any of the forms of PA. Therefore, we did not include these variables in the multifactorial models.

\section{DISCUSSION}

A meta-analysis showed that a high proportion of college students is physically inactive, and college students' PA requires more attention (34). The current study bridges the knowledge gaps to examine and compare the levels, correlates and gender differences of five PA forms across nine universities in Libya where no comparable data exist.

In connection with objective one, in the current sample, $4.8 \%$ of students (2.4\% of females, $9.6 \%$ of males) achieved the MPA recommendations of the American College of Sport Medicine and American Heart Association (20). This is lower than in Saudi Arabia ( $25 \%$ of females, $50 \%$ of males met the recommendations of 1 hour MPA daily) (35); and also lower than in the UK (24), where $12.4 \%$ achieved the same MPA guidelines (20). However, in the Libyan sample, another $20.7 \%$ achieved the recommended level of walking, which can also be considered as a form of MPA. Taking this into account, MPA levels might even be higher in Libyan than in UK students. Others have noted that the prevalence of sufficient PA differed greatly depending on the definition used (36). Our data suggested that among Libyan students, walking is a predominant form of MPA, perhaps reflective of the lower level of public transport and/or cultural norms regarding active transport, when compared to the UK.

As for VPA, $11.2 \%$ of our sample (5.6\% of females, $22.1 \%$ of males) achieved the recommended VPA guidelines, much lower than UK students, where $33.1 \%$ achieved the guidelines of VPA $(20,24)$. In relation to MSPA, $43.7 \%$ of our sample achieved the guidelines of MSPA - higher than the UK where $23.9 \%$ achieved the MSPA guidelines (24). For MVPA, $28.5 \%$ of our sample achieved the MVPA guidelines. This combined MVPA measure generally resulted in a higher prevalence of PA than the different forms of PA individually. In addition, lower differences between gender and regions were noted when using the combined measure MVPA, but the differences still remained significant. In agreement with our sample's $28.5 \%$ achieving the MVPA guidelines, others found that only $33 \%$ of students met the MVPA guidelines (37). There are generally low MPA and VPA levels in university students $(38,39)$. 
Table 3. Adjusted odds ratios for variables associated with achieving recommended levels of five forms of $P A$ *

\begin{tabular}{|c|c|c|c|c|c|}
\hline & $\begin{array}{c}\text { Walking } \\
\text { OR (95\% Cl) }\end{array}$ & $\begin{array}{c}\text { Moderate PA } \\
\text { OR (95\% Cl) }\end{array}$ & $\begin{array}{l}\text { Vigorous PA } \\
\text { OR (95\% CI) }\end{array}$ & MVPA & $\begin{array}{c}\text { Muscle } \\
\text { strengthening PA } \\
\text { OR }(95 \% \mathrm{Cl})\end{array}$ \\
\hline Keep an eye on health ${ }^{a}$ & $0.93(0.78-1.11)$ & $0.92(0.72-1.19)$ & $1.40(1.09-1.81)$ & $1.08(0.91-1.27)$ & $1.68(1.43-1.97)$ \\
\hline $\begin{array}{l}\text { Academic performance } \\
\text { compared to peers }^{b}\end{array}$ & $1.16(0.98-1.37)$ & $0.98(0.78-1.24)$ & $1.06(0.85-1.32)$ & $1.08(0.93-1.26)$ & $1.29(1.12-1.50)$ \\
\hline Gender (Male) & $1.20(0.89-1.61)$ & $1.69(1.13-2.53)$ & $4.28(2.92-6.27)$ & $2.02(1.56-2.63)$ & $3.32(2.59-4.28)$ \\
\hline \multicolumn{6}{|l|}{ Region } \\
\hline North (reference) & 1.00 & 1.00 & 1.00 & 1.00 & 1.00 \\
\hline South & $0.88(0.59-1.31)$ & $0.63(0.34-1.17)$ & $0.59(0.34-1.04)$ & $0.75(0.52-1.09)$ & $0.97(0.67-1.39)$ \\
\hline East & $0.60(0.36-0.99)$ & $1.12(0.46-2.74)$ & $0.31(0.13-0.76)$ & $0.56(0.35-0.89)$ & $0.45(0.28-0.72)$ \\
\hline West & $0.57(0.41-0.81)$ & $0.55(0.34-0.86)$ & $0.67(0.44-1.02)$ & $0.57(0.42-0.77)$ & $1.06(0.78-1.45)$ \\
\hline Nagelkerke $\mathrm{R}^{2}$ & 0.02 & 0.11 & 0.14 & 0.15 & 0.17 \\
\hline Homer \& Lemeshow** & 0.09 & 0.27 & 0.06 & 0.12 & 0.62 \\
\hline
\end{tabular}

= any moderate or vigorous PA; a some extent/very much; ${ }^{\mathrm{b}}$ from much worse to much better; ${ }^{*}$ cells represent $\mathrm{p}$-value.

A point is that while the Libyan sample exhibited lower VPA levels than the UK, Libyan students, at the same time, achieved higher MSPA levels than UK students (24). MSPA could be undertaken more conveniently by individuals within the privacy of their own homes (as opposed to MPA/VPA undertaken in gyms, fitness clubs and venues, or in the street), hence this findings suggested that cultural issues and availability/social acceptability of such venues, could be at play. Across Libya, it is not common to see individuals jogging in the streets, and even much less so for females. This might be possibly due to prevalent cultural norms, and probably religion particularly for Libyan Muslim females living in a predominantly Muslim society. Women in many Islamic countries are accompanied by a male family member (husband, father, brother) when going outdoors which decreases opportunities for PA (11), and for public modesty, many Arabic women wear traditional dress (abayas) which renders it arduous to partake in certain types of physical activities (40). Hence females seem to have less opportunities to engage in PA. Others found that participants recognized the importance of PA in chronic disease prevention, yet most were not regularly physically active, which might be explained by the fact that many participants lived in an extended-family setting that underscored the importance of PA (9). Women often found themselves exercising at odd hours so that neighbours would not notice them. Students' access to safe and culturally appropriate exercise facilities requires attention (9).

It was not feasible for the authors to access the websites of the participating Libyan universities (Table 1) to see whether students were offered PA engagement opportunities, and whether gender specific exercise/sport programmes or facilities were available. First hand experiences of the first author and anecdotal observations of the second author (native of Libya) suggest that fitness venues/gyms are not common in Libya, probably even less in the Southern cities (located 'deeper' in the Sahara desert), and definitely not sufficiently accessed by females. Indeed, youth (15-19 years) living in rural desert areas were less physically active than those living in urban or rural farm environments (6). These features need consideration within a raft of issues of Libya's geopolitical situation, prevalent cultural norms, and prevailing religious Islamic faith. This pertains to the Islamic Arabic terms 'mubah' (action that is neither forbidden nor recommended, religiously neutral), 'makruh' (disliked or offensive act, literally "detestable"), and 'haram' (act that is forbidden in the religious texts, the highest status of prohibition) - behaviours that could present additional barriers to performing PA given the constraints of Libyan daily life. Where feasible and available, we browsed the websites of the participating Libyan universities, and none of the websites appeared to indicate PA programmes, interventions or access opportunities on campus.

For objective two, we assessed the variables associated with achieving the guidelines of five PA forms. Regarding the demographic variables, males were positively associated with MPA and VPA, and also highly associated with MSPA. These findings agree with the UK, where males were positively associated with MPA, VPA, MVPA and MSPA (24). However, for the Libyan sample, the odds ratios for males for the different PA forms were much greater than in the UK. This big gender odds ratio further supports the assumptions regarding cultural differences and the low prevalence of Libyan females who undertake some form of PA.

Other studies in the Eastern Mediterranean Region are few but generally support the higher PA level in boys than in girls, for instance, there were significant differences between males and females in Kuwait, where males exhibited higher overall PA values than females (13). Similarly, across students in the United Arab Emirates, VPA was performed more by males than females (39). However, at the general population level, research in Nigeria reported no significant differences in prevalence of PA between men and women (14).

As for the academic performance variables, we found that the variable 'academic performance compared to peers' was positively associated with MSPA. This is in contrast with the UK where academic performance was not associated with any of three PA forms (24). Nevertheless, others found positive relationships between PA and educational achievement, although not directly linked to strengthening exercises. In Finland, selfreported PA was directly associated with academic achievement; but, objectively measured PA was not associated with academic 
achievement (17). Researches also found that adolescents who spent more time physically inactive were likely to achieve below average academically (18). Conversely, no correlation was found between health-promoting lifestyle variables (including PA) and academic performance measured as grade point average (13). Such inconsistencies in the PA - academic achievement relationships are not surprising. El Ansari and Stock (19) highlighted that the associations between health variables generally and academic achievement were not straightforward to tease out, and were sensitive to the type/nature of academic achievement indicator/s that are employed (e.g. subjective or objective indicators of achievement).

For the health variables, we found that health awareness (keep an eye on health) was positively associated with VPA and more strongly associated with MSPA. We agree with the UK study, where health awareness (measured by the same item) was positively associated with MPA and VPA (24). No other health-related variables we examined were significantly associated with PA. For instance, for BMI, in the current sample (24\% of females and $36 \%$ of males) were either overweight/obese. These levels are different to the levels of students enrolled at nine faculties in Egypt (study was undertaken at about the same time, 2009-2010), where more females than males were either overweight or obese (22). The fact that BMI was not associated with PA agrees with other research showing inconsistent results (41). In addition, while PA contributes to quality of life (QoL), and that social and emotional benefits are primary motivators and outcomes for participants (15), we did not find an association between QoL and PA. We also failed to find association with age or year of study while others reported a decrease of PA with increasing year of study (3), and there was a slight decrease in PA among students $>20$ years old compared to those $<20$ years old (39). Perhaps our students' age range was too 'narrow' to observe associations between PA and age/study year.

The study has limitations. Many variables are associated with PA, e.g. biological (sex, BMI, parental BMI), social - parents' social status (education, income), behavioural (TV/computer habits, method of commuting to university, sports club membership, time outdoors), physical environmental (rural vs. urban), psychological (emotional symptoms, self-esteem), and seasonal variables (summer vs. winter) (16). Due to respondent burden, we only examined selected groups of variables. The study is crosssectional, no causal relationships can be derived (42). Females were over-represented; hence the main results were stratified/ adjusted for sex. This sample remains a convenience sample. Selection bias due to the fact that students with health problems may be less likely to be present in class when the data was collected cannot be ruled out. Self-reporting estimated the PA levels, and objective PA measurement was not undertaken (due to the study's large sample size, questionnaires were more feasible). Future research could address these limitations.

Despite these limitations the study has important strengths. The large sample size (and representativeness) permit the calculation of precise estimates for the different variables. The study's findings confirm some of the relationships but, in contrast to other research, in the current survey, multiple variables that could potentially be associated with PA in university students were considered simultaneously (adjusted model). This adjustment could result in fewer significant associations than with other strategies, e.g. univariate analysis. No previous study investigated in detail levels, gender differences and correlates of PA at Libyan universities.

\section{CONCLUSION}

Understanding the correlates of PA can help inform and improve programmes that promote PA among youth. Our findings contribute to the evidence base necessary for appropriate PA interventions for such young adult populations, specifically in higher education institutions. Evidence based PA intervention/s at university campuses are highly recommended to attempt to increase the low PA level across the Libyan university students. Such interventions would need to be attractive and acceptable to the students, and should be adapted to the existing cultural norms. The aim is to provide appropriate opportunities, e.g. walking or gender specific exercise groups, particularly to encourage female students to engage in different forms of both MPA and VPA without conflicting with Muslim traditions. Such strategies would need to be delivered in conjunction with national policies that promote active living.

\section{Acknowledgement}

The authors acknowledge the students and universities and colleges that participated in this study.

\section{Conflict of Interest}

None declared

\section{REFERENCES}

1. Kohl HW 3rd, Craig CL, Lambert EV, Inoue S, Alkandari JR, Leetongin G, et al.; Lancet Physical Activity Series Working Group. The pandemic of physical inactivity: global action for public health. Lancet. $2012 \mathrm{Jul}$ 21;380(9838):294-305.

2. Nelson TF, Gortmaker SL, Subramanian SV, Wechsler H. Vigorous physical activity among college students in the United States. J Phys Act Health. 2007 Oct;4(4):495-508.

3. Small M, Bailey-Davis L, Morgan N, Maggs J. Changes in eating and physical activity behaviors across seven semesters of college: living on or off campus matters. Health Educ Behav. 2013 Aug;40(4):435-41.

4. Musaiger AO, Al-Hazzaa HM, Takruri HR, Mokhatar N. Change in nutrition and lifestyle in the eastern mediterranean region: health impact. J Nutr Metab. 2012;2012:436762.

5. Al-Hazzaa HM, Musaiger AO; Arab Teens Lifestyle Study Research Group. Physical activity patterns and eating habits of adolescents living in major Arab cities. The Arab Teens Lifestyle Study. Saudi Med J. 2010 Feb;31(2):210-1.

6. Al-Nuaim AA, Al-Nakeeb Y, Lyons M, Al-Hazzaa HM, Nevill A, Collins $P$, et al. The Prevalence of physical activity and sedentary behaviours relative to obesity among adolescents from Al-Ahsa, Saudi Arabia: rural versus urban variations. J Nutr Metab. 2012;2012:417589.

7. Abolfotouh MA, Bassiouni FA, Mounir GM, Fayyad RCh. Health-related lifestyles and risk behaviours among students living in Alexandria University Hostels. East Mediterr Health J. 2007 Mar-Apr;13(2):376-91.

8. Khalaf A, Ekblom Ö, Kowalski J, Berggren V, Westergren A, Al-Hazzaa $\mathrm{H}$. Female university students' physical activity levels and associated factors - a cross-sectional study in southwestern Saudi Arabia. Int J Environ Res Public Health. 2013 Aug 9;10(8):3502-17.

9. Shuval K, Weissblueth E, Araida A, Brezis M, Faridi Z, Ali A, et al. The role of culture, environment, and religion in the promotion of physical activity among Arab Israelis. Prev Chronic Dis. 2008 Jul;5(3):A88.

10. Amine EK, Samy M. Obesity among female university students in the United Arab Emirates. J R Soc Health. 1996 Apr;116(2):91-6.

11. Benjamin K, Donnelly TT. Barriers and facilitators influencing the physical activity of Arabic adults: A literature review. Avicenna. 2013;(8):doi:10.5339/avi.2013.8.

12. Bauman AE, Reis RS, Sallis JF, Wells JC, Loos RJ, Martin BW; Lancet Physical Activity Series Working Group. Correlates of physical activity: why are some people physically active and others not? Lancet. 2012 Jul 21;380(9838):258-71. 
13. Al-Kandari F, Vidal VL. Correlation of the health-promoting lifestyle, enrollment level, and academic performance of College of Nursing students in Kuwait. Nurs Health Sci. 2007 Jun;9(2):112-9.

14. Oyeyemi AL, Oyeyemi AY, Jidda ZA, Babagana F. Prevalence of physical activity among adults in a metropolitan Nigerian city: a cross-sectional study. J Epidemiol. 2013;23(3):169-77.

15. Gill DL, Hammond CC, Reifsteck EJ, Jehu CM, Williams RA, Adams MM, et al. Physical activity and quality of life. J Prev Med Public Health. 2013 Jan;46 Suppl 1:S28-34.

16. Lowry R, Lee SM, Fulton JE, Demissie Z, Kann L. Obesity and other correlates of physical activity and sedentary behaviors among US high school students. J Obes. 2013;2013:276318.

17. Syväoja HJ, Kantomaa MT, Ahonen T, Hakonen H, Kankaanpää A, Tammelin TH. Physical activity, sedentary behavior, and academic performance in Finnish children. Med Sci Sports Exerc. 2013 Nov;45(11):2098104.

18. Shin YS, So WY. Association between physical inactivity and academic record in Korean adolescents. Iran J Public Health. 2012;41(10):36-42.

19. El Ansari W, Stock C. Is the health and wellbeing of university students associated with their academic performance? Cross sectional findings from the United Kingdom. Int J Environ Res Public Health. 2010 Feb;7(2):509-27.

20. Haskell WL, Lee IM, Pate RR, Powell KE, Blair SN, Franklin BA, et al.; American College of Sports Medicine; American Heart Association. Physical activity and public health: updated recommendation for adults from the American College of Sports Medicine and the American Heart Association. Circulation. 2007 Aug 28;116(9):1081-93.

21. El Ansari W, Maxwell AE, Mikolajczyk RT, Stock C, Naydenova V, Krämer A. Promoting public health: benefits and challenges of a Europeanwide research consortium on student health. Cent Eur J Public Health. 2007 Jun;15(2):58-65.

22. El Ansari W, Labeeb S, Moseley L, Kotb S, El-Houfy A. Physical and psychological well-being of university students: survey of eleven faculties in Egypt. Int J Prev Med. 2013 Mar;4(3):293-310.

23. El Ansari W, Sebena R, Stock C. Socio-demographic correlates of six indicators of alcohol consumption: survey findings of students across seven universities in England, Wales and Northern Ireland. Arch Public Health. 2013 Nov 6;71(1):29.

24. El Ansari W, Stock C, John J, Deeny P, Phillips C, Snelgrove S, et al. Health promoting behaviours and lifestyle characteristics of students at seven universities in the UK. Cent Eur J Public Health. 2011 Dec;19(4):197-204

25. El Ansari W, Stock C, Phillips C, Mabhala A, Stoate M, Adetunji H, et al Does the association between depressive symptomatology and physical activity depend on body image perception? A survey of students from seven universities in the UK. Int J Environ Res Public Health. 2011 Feb;8(2):281-99.

26. El Ansari W, Stock C; UK Student Health Group, Snelgrove S, Hu X, Parke S, et al. Feeling healthy? A survey of physical and psychological wellbeing of students from seven universities in the UK. Int J Environ Res Public Health. 2011 May;8(5):1308-23.

27. El Ansari W, Stock C, Mikolajczyk RT. Relationships between food consumption and living arrangements among university students in four European countries - a cross-sectional study. Nutr J. 2012 Apr 24;11:28.
28. El Ansari W, Stock C, Mills C. Is alcohol consumption associated with poor academic achievement in university students? Int J Prev Med. 2013 Oct;4(10):1175-88.

29. El Ansari W, Oskrochi R, Stock C. Symptoms and health complaints and their association with perceived stress: students from seven universities in England, Wales and Northern Ireland. J Public Health. 2013;21(5):413-25.

30. Potthoff P, Schroeder E, Reis U, Klamert A. Process and results of field work concerning the Federal Health Survey. Gesundheitswesen. 1999 Dec;61 Spec No:S62-7. (In German.)

31. American College Health Association; National College Health Assessment. Reference group data report 2005 [Internet]. Baltimore: American College Health Association; 2006 [cited 2013 May 14]. Available from: http://www.acha-ncha.org/docs/ACHA-NCHA_Reference_Group_Report_Fall2005.pdf.

32. Bruusgaard D, Nessiøy I, Rutle O, Furuseth K, Natvig B. Measuring functional status in a population survey. The Dartmouth COOP functional health assessment charts/WONCA used in an epidemiological study. Fam Pract. 1993 Jun;10(2):212-8.

33. World Health Organization. Obesity: preventing and managing the global epidemic. Geneva: WHO; 2000.

34. Keating XD, Guan J, Piñero JC, Bridges DM. A meta-analysis of college students' physical activity behaviors. J Am Coll Health. 2005 SepOct;54(2):116-25

35. Al-Hazzaa HM, Abahussain NA, Al-Sobayel HI, Qahwaji DM, Musaiger AO. Physical activity, sedentary behaviors and dietary habits among Saudi adolescents relative to age, gender and region. Int J Behav Nutr Phys Act. 2011 Dec 21;8:140.

36. Scheers T, Philippaerts R, Lefevre J. Compliance with different physical activity recommendations and its association with socio-demographic characteristics using an objective measure. BMC Public Health. 2013 Feb 14;13:136.

37. Shuval K, Weissblueth E, Brezis M, Araida A, Dipietro L. Individual and socio-ecological correlates of physical activity among Arab and Jewish college students in Israel. J Phys Act Health. 2009 May;6(3):306-14.

38. Musharrafieh U, Tamim HM, Rahi AC, El-Hajj MA, Al-Sahab B, et al. Determinants of university students physical exercise: a study from Lebanon. Int J Public Health. 2008;53(4):208-13.

39. Muttappallymyalil J, Mathew E, Sreedharan J, Al Sharbatii S, Shaikh RB, Basha SA. Self reported physical activity among University Students in Ajman, UAE. Pak J Med Sci. 2010 Oct;26(4):782-6.

40. Nakamura Y. Beyond the hijab: female Muslims and physical activity. WSPAJ. 2002;11(2):21-48.

41. Van Der Horst K, Paw MJ, Twisk JW, Van Mechelen W. A brief review on correlates of physical activity and sedentariness in youth. Med Sci Sports Exerc. 2007 Aug;39(8):1241-50.

42. El Ansari W, Sebena R, Stock C. Do importance of religious faith and healthy lifestyle modify the relationships between depressive symptoms and four indicators of alcohol consumption? A survey of students across seven universities in England, Wales, and Northern Ireland. Subst Use Misuse. 2014 Feb;49(3):211-20.

Received February 1, 2014 Accepted in revised form April 3, 2014 